\section{Access to flucytosine for HIV-infected patients with cryptococcall meningitis - an urgent need}

To the Editor: The addition of oral flucytosine to an amphotericin B-containing induction regimen for HIV-associated cryptococcal meningitis (CM) is associated with improved fungal clearance and a $39 \%$ reduction in 10 -week mortality. ${ }^{[1]}$ Owing to the unacceptably high mortality associated with CM, access to flucytosine needs to be prioritised in South Africa (SA), together with interventions such as earlier detection of cryptococcal disease. ${ }^{[2]}$ The World Health Organization (WHO) recommended amphotericin B and flucytosine as the preferred induction regimen in rapid advice guidelines, and in 2013 included these agents in the WHO Model Lists of Essential Medicines as part of the 'core list.. ${ }^{[3,4]}$ In line with WHO recommendations, the Southern African HIV Clinicians Society has strongly supported efforts to obtain access to flucytosine in updated clinical guidelines. ${ }^{[5]}$ In 2012, amphotericin B was prescribed for more than $80 \%$ of patients with CM at predominantly urban sentinel hospitals. ${ }^{[6]}$ The addition of flucytosine would not add much complexity to this regimen. In a resource-limited setting, Day et al. ${ }^{[1]}$ showed that it was feasible to use flucytosine instead of amphotericin
B monotherapy with no additional toxicity and with the same panel of monitoring blood tests, i.e. full blood count and urea, electrolytes and creatinine.

Even though flucytosine is a simple, off-patent agent that has been in clinical use for over five decades, ${ }^{[7]}$ there are two major barriers to access in SA. First, while flucytosine is still registered with the Medicines Control Council (MCC), this registration has not been maintained. As a distributor for the innovator company, Roche first registered flucytosine with the MCC in the 1990s, but withdrew the product from the market in the early 2000s. Currently, flucytosine is only available for compassionate use through an MCC application (section 21 of the Medicines and Related Substances Control Act 1965), a process that may take several weeks. Second, US Food and Drug Administration (FDA)-approved flucytosine obtained through the innovator company, Meda Pharmaceuticals/Valeant, or a US-based generic manufacturer, Sigmapharm Laboratories, is expensive. ${ }^{[8]}$ Based on an approximate price of R13.00 per $500 \mathrm{mg}$ tablet, a 14-day treatment course for a $50 \mathrm{~kg}$ adult at a dose of $100 \mathrm{mg} / \mathrm{kg} / \mathrm{d}$ would cost R1 820.00 ${ }^{[8]}$ Since amphotericin B currently costs approximately R700.00 for 14 days, adding R1 820.00 inflates the drug cost of induction-phase treatment by $>300 \% .{ }^{[9]}$ Loyse et al. ${ }^{[10]}$ have suggested that high costs have persisted as a result of a market failure. However, demand for flucytosine can be reinvigorated: surveillance case numbers can be used for drug forecasting by manufacturers (approximately 7000 cases were diagnosed in 2012 $2^{[6]}$ ), best clinical practice guidelines have been developed, ${ }^{[5]}$ and pooled procurement of flucytosine with other anti-infective agents may increase bargaining power.

While few manufacturers have expressed interest in production of low-cost generic flucytosine, local distributors have expressed willingness to negotiate with manufacturers of FDA-approved flucytosine and apply for fast-track updated registration of the drug. If these efforts are successful, we motivate that flucytosine should be included in the SA Essential Medicines List for hospitals, along with amphotericin B.

\section{Nelesh P Govender}

National Institute for Communicable Diseases - Centre for Opportunistic, Tropical and Hospital Infections, National Health Laboratory Service and Faculty of Health Sciences, University of the Witwatersrand, Johannesburg, South Africa neleshg@nicd.ac.zo

\section{Graeme Meintjes}

Institute of Infectious Disease and Molecular Medicine and Department of Medicine, University of Cape Town, South Africa, and Department of Medicine, Imperial College London, UK

\section{Shabir Banoo}

Right to Care and Faculty of Health Sciences, University of the Witwatersrand Johannesburg, South Africa

1. Day IN, Chau TT, Wolbers $\mathrm{M}$, et al. Combination antifungal therapy for cryptococcal meningitis. $\mathrm{N}$ Engl J Med 2013;368(14):1291-302. [http://dx.doi.org/ 10.1056/NEJMc1305981]

2. Govender NP, Roy M, Oladoyinbo S, et al. Phased implementation of screening for cryptococcal disease in South Africa. S Afr Med J 2012;102(12):914-917. [http://dx.doi.org/ 10.7196/samj.6228

3. World Health Organization. Rapid Advice - Diagnosis, Prevention and Management of Cryptococcal Disease in HIV-infected Adults, Adolescents and Children. Geneva: WHO, 2011. http://www.who.int/ hiv/pub/cryptococcal_disease2011/en/(accessed 25 July 2014).

4. World Health Organization. WHO Model Lists of Essential Medicines. Geneva: WHO, 2014. http:// www.who.int/medicines/publications/essentialmedicines/en/ (accessed 25 July 2014).

5. Govender NP, Meintjes G, Bicanic T, et al. Guideline for prevention, diagnosis and management of cryptococcal meningitis among HIV-infected persons: 2013 update. Southern African Journal of HIV Medicine 2013;14(2):76-86. [http://dx.doi.org/10.7196/SAJHIVMED.930]

6. National Institute for Communicable Diseases. GERMS-SA Annual Report 2012. Johannesburg: National Institute for Communicable Diseases, 2012. www.nicd.ac.za/assets/files/2012_GERMS-SA Annual_Report.pdf (accessed 25 July 2014).

7. Annual_Report.pdf (accessed 25 July 2014). . Loyse A, Dromer F, Day J, Lortholary O, Harrison TS. Flucytosine and cryptococcosis: Time to
urgently address the worldwide accessibility of a 50-year-old antifungal. J Antimicrob Chemother 2013;68(11):2435-2444. [http://dx.doi.org/ 10.1093/jac/dkt221] 
8. Loyse A, Thangaraj H, Easterbrook P, et al. Cryptococcal meningitis: Improving access to essential antifungal medicines in resource-poor countries. Lancet Infect Dis 2013;13(7):629-637. [http://dx.doi.org/10.1016/S1473-3099(13)70078-1]

9. Bicanic T, Wood R, Bekker LG, Darder M, Meintjes G, Harrison TS. Antiretrovira

Bicanic I, Wood R, Bekker LG, Darder M, Meintjes G, Harrison IS. Antiretrovira roll-out, antifungal roll-back: Access to treatment for cryptococcal meningitis. Lancet Infect Dis 2005;5(9):530-531. [http://dx.doi.org/10.1016/S1473-
3099(05)70197-3]

10. Loyse A, Bicanic T, Jarvis JN. Combination antifungal therapy for cryptococcal meningitis. N Engl J Med 2013;368(26):2522-2523. [http://dx.doi.org/ 10.1056/ NEJMc1305981\#SA1

S Afr Med J 2014;104(9):594-595. DOI:10.7196/SAMJ.8713 